\title{
Software Agents for Managing Learning Plans
}

\author{
I. T. Hawryszkiewycz \\ Department of Information Systems, \\ University of Technology, Sydney
}

\author{
igorh@it.uts.edu.au
}

\begin{abstract}
Support for personalized learning requires further assistance than currently available with most learning management system. Software agents have been proposed as one way of providing such assistance. The paper identifies three kinds of software agents, pedagogical, function and process agents. The paper then concentrates on process agents, which guide learners to develop personalized preferred learning plans that match learner needs and then manage progress through such plans. Agent support will only be practical if widely applicable generic agents, which can be reused in many plans, can be identified. Such agents can then be adapted to particular learner needs without extensive programming. The paper identifies some generic agents for this purpose and concentrate on agents that manage progress through the learning plans.
\end{abstract}

Keywords: Learning process, software agents, modelling

\section{Introduction}

Demands for more customized learning will require new ways to support learning processes. Such demands may be to acquire particular competencies (Hezemans and Ritzen, 2002) or knowledge of new subject areas. Educational approaches are also placing more emphasis on constructivist learning approaches (Jonassen, 2002), where learners construct knowledge in their preferred ways. A learner sets their learning goal and develops a learning plan and is provided with learning materials. In educational institutions, the learning plan is usually a set of lectures and assessments that is followed by all the students taking a subject. We address ways to customize such plans to specialized learner needs for large numbers of learners. The learners are then guided through their specialized plan using support systems to minimize the effort needed to manage the plans by teachers. Such guidance can take many forms. It may be to identify a lack of some elementary knowledge and provide ways to build familiarity of this knowledge before continuing with the main learning plan. One further advantage in formulating plans is support constructivist learning, which some writers (Petraglia, 1998) suggest are not effectively supported in current systems.

Material published as part of this publication, either on-line or in print, is copyrighted by the Informing Science Institute. Permission to make digital or paper copy of part or all of these works for personal or classroom use is granted without fee provided that the copies are not made or distributed for profit or commercial advantage AND that copies 1) bear this notice in full and 2) give the full citation on the first page. It is permissible to abstract these works so long as credit is given. To copy in all other cases or to republish or to post on a server or to redistribute to lists requires specific permission and payment of a fee. Contact Publisher@InformingScience.org to request redistribution permission.
New kinds of support systems are needed for personalized learning. It will be prohibitively expensive to use current techniques. One teacher obviously is limited in the number of students, each following their personal program that they can support. Agent systems can provide better support here as they can provide greater flexibility in the way learners utilize services provided by learning management systems. Agent 
systems have been suggested earlier. One are the pedagogical agents (Baylor, 2003) such as expert, motivator or mentor. Another are agents that support specific functions (McArdle, 2005), such as interface or navigational agents. The paper proposes a third class of agents, namely process agents. Process agents guide users through a process and are generic in the sense that they are domain independent. They do not contain domain knowledge but simply assist learners and teachers to proceed through the learning process. They assist learners to get access to materials, and where necessary create their learning plans.

Two classes of process agents have been identified earlier (Hawryszkiewycz, 2005a). One are agents that assist a learner to construct a learning plan. The other are agents that manage the learning plan and dynamically amend the plan as needed. Earlier work has described agents that assist learners to create their learning plans. The paper concentrates on agents that manage learning plans.

\section{Defining the Process}

Our first step in defining generic agents is to define a taxonomy, or grammar, for describing leaning processes. The grammar or taxonomy will provide a fundamental set of concepts that serve as the framework for generic agent systems. The main elements, or learning process concepts, of such a grammar for the learning process are shown in Figure 1. These include:

Learning environment, or where learning takes place. This may be a University of a person's place of work.

Learning goal, which describes the learning objective,

Learning plan, which defines the sequence of learning activities to be followed to achieve the learning goal.

Learning activity, which describes a step of the learning plan; this may be create a report, evaluate a problem,

Subject metadata, which provides explicit references to information needed in the activity,

The learning method, which will be used in the learning step,

Support services provided for the learning method.

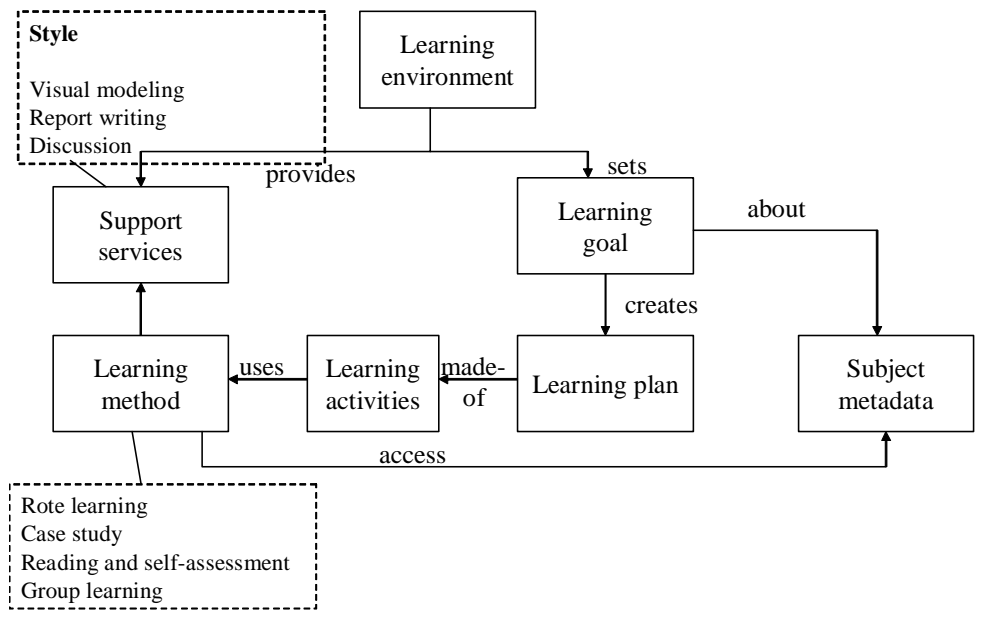

Figure 1 -Learning Process Concepts 
The general semantic here is that a learner specifies a learning goal. A plan, which is made up of a number of learning activities, is then constructed by the learner with assistance from an agent. Each activity has a learning subgoal and specifies the preferred learning method to be used by the learner. Wang (2005) defines a similar set made up of units (corresponding to our learning plans), activities (corresponding to our learning activities), and facilities (corresponding to our methods).

Figure 2 shows an outline of the learning process that is made up of the elements shown in Figure 1. Here the learner sets a goal. An agent then assists the learner to set up a learning plan. The agent uses the learner profile to select the necessary learning activities to address learner knowledge gaps. It also uses the learner's preferred learning style to select the best learning method. The learner is then assisted by managing agents to proceed through a number of planned activities. The activity results in the creation of activity records, which can be artifacts that must be produced as part of the activity. It also includes an evaluation step. The plan can of course be changed to do some additional catch up work if indicated during the evaluation.

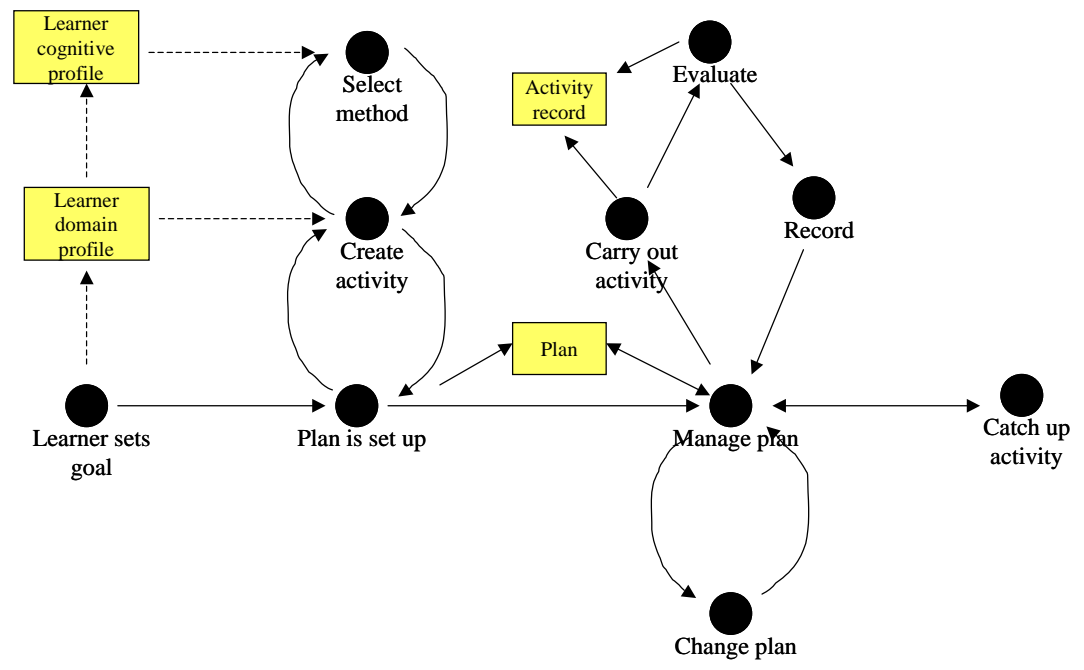

Figure 2 - General framework for agent support

\section{The Learning Plan}

There can of course be more than one alternate plan for the same learning goal. Figure 3, for example, shows alternate plans for learning on how to integrate knowledge management into ebusiness applications. One approach is the case study approach, whose goal is to identify and generalize ways in where knowledge management has been shown to provide advantages. Thus one step here is to read a number of case studies to identify successful implementation and from these develop some conclusions about ways to use knowledge to advantage in a variety of business situations.

The other plan is a standard modeling approach. Here a system model is developed followed by design, which stresses innovations in the use of knowledge management. A new design is then proposed and evaluated. 


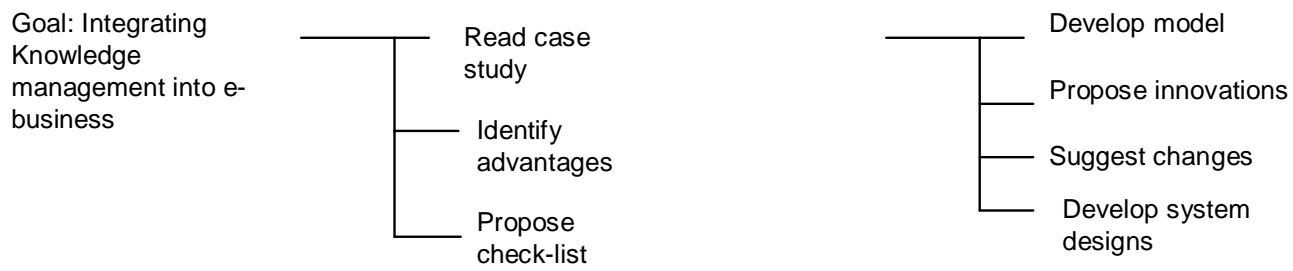

Figure 3 - Alternate plans, an example

In either case, the learning plan is made up of a number of learning activities. This plan is then implemented as a learning plan on the computer support system. Figure 4 shows an example learning plan for the second option in Figure 3. It shows the steps of the plan and their particular start and finish times. Each step also includes the materials needed in the step and the outcomes to be produced.

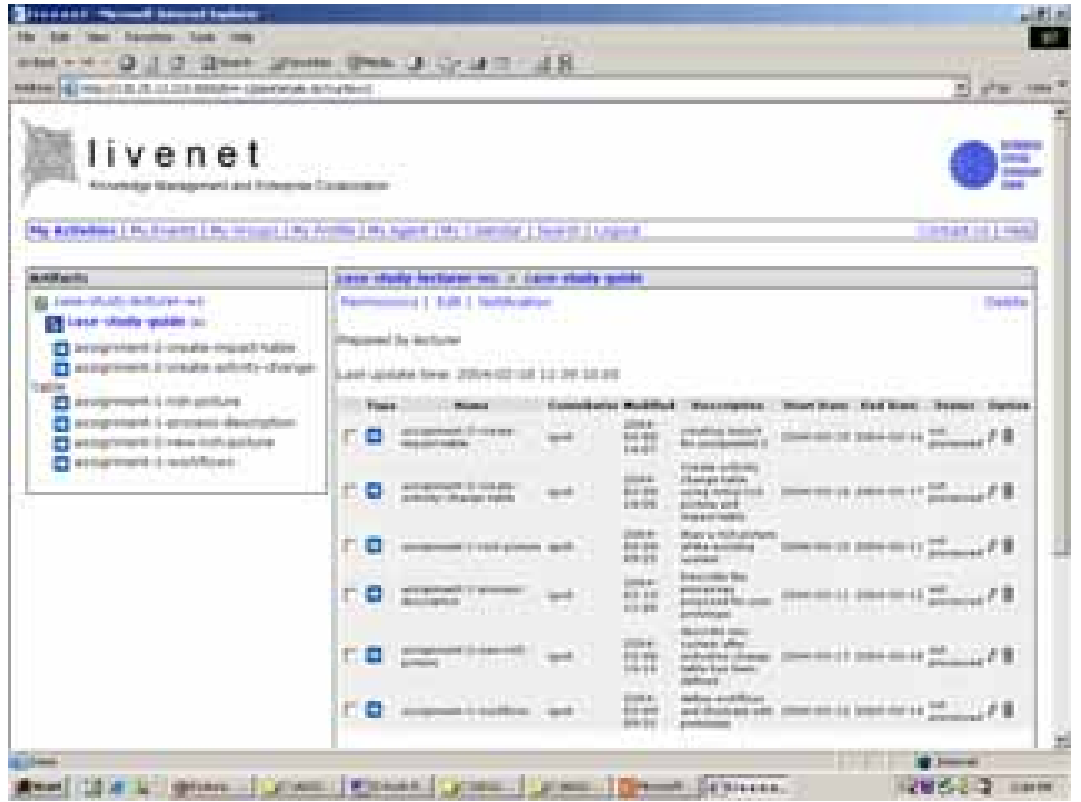

Figure 4 - The learning plan

\section{Managing the Learning Plan using Process Agents}

This paper concentrates on using agents for learning plan management. The goal is not to define specific agents for each learning plan but to have a set of generic agents that can be put together to support any learning process. Thus there will be a generic agent to support any learning activity, a generic agent to support a learning plan, and so on. This theoretical approach here is illustrated in Figure 5.

It is based on our learning process concepts defined in Figure 1. It then uses the metamodel of collaboration defined in earlier work, which identified the concepts to describe collaborative processes. These included roles, groups, work-items, work-activities among others (Hawryszkiewycz, 2005b). The collaborative metamodel concepts identify candidates for generic agents (Hawryszkiewycz \& Lin, 2003) and typical multi-agent architectures. Typical agents here include a role agent, a group agent, a work-item agent or an activity agent. 
Any process can then be expressed in collaborative concepts. Generic agents are chosen to correspond to these concepts. In our case, a learning process can then be converted into a model expressed in terms of collaborative concepts. The corresponding generic agents can then be selected and customized for each element of the learning process. These generic agents are then combined in a multi-agent architecture to support a learning environment. They are then implemented on our system, LiveNet (http://livenet4.it.uts.edu.au).

Based on such conversions, the following generic agents have been selected (Hawryszkiewycz, 2005a) to assist in managing the learning process:

An activity agent, which manages a learning plan,

Work-item agents, each of which manage one learning activity,

Work-item agents, each of which manage one learning method,

An artifact agent, which manages an artifact that may be produced as part of learning and which serves as a check-list for building knowledge,

A personal agent that supports the learner.

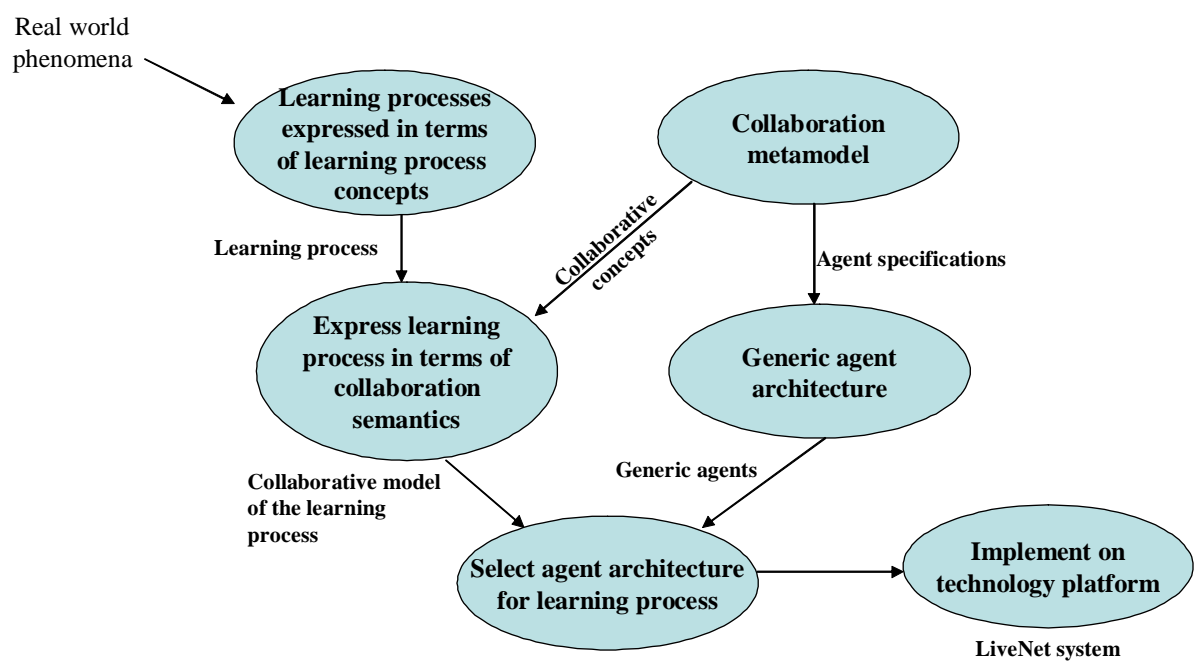

Figure 5 - Theoretical approach

The way that agents interact with each other in a multi-agent architecture is shown in Figure 6 as follows:

The learning plan agent delegates work to learning activities by creating a workspace for the learning activity and its agent,

The learning plan agent monitors progress on the learning activity task,

The artifact agent serves as the collection of knowledge developed by the learner. It interacts with the learning plan agent to identify knowledge needs. The learning plan agent then sets up a learning activity to acquire this knowledge,

The learning activity agent can interact with the learner agent to find the learner's background when choosing the next learning activity, 
The learning activity agent can initiate any support activity such as situation assessment as needed.

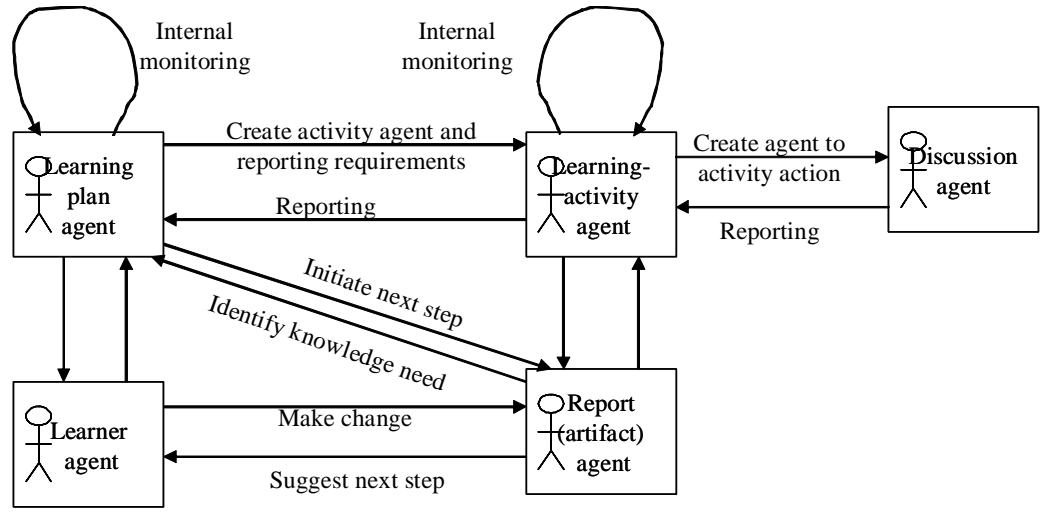

Figure 6 - Multi-agent structure for learner support

We use the usual reasoning model of agents where an agent goal leads to a plan, which is defined in terms of rules that lead to actions. The plan itself can have lower level goals. The reasoning model is implemented using the three-layer architecture (Müller, 1996) chosen from a number of alternative architectures (Wooldridge, 1999). Agents are used to achieve goals using plans defined by agent users. A plan is composed of event-condition-action rules, each of which specifies the actions to be executed when condition is true. We can predefine the goal, belief, plan, rule, and action for an agent or define them at run time.

\section{Learning Plan Agent - Creating Learning Activities}

The learning plan agent would include the rules of actions to take when progress is not as expected. These would include:

Goal: Complete the learning plan;

Plan: for completing learning plan.

Subgoal g1: determine if next activity is to be started;

Subgoal g2: determine if additional learning activity is needed;

Subplan: for identifying additional activity

Rule: if next artifact step needs ' $a$ ' and learner has no ' $a$ ' knowledge then action start activity to learn ' $a$ ';

Subgoal g3: determine if expert advice is needed;

The agent that manages the plan creates workspaces for each activity. The workspace in Figure 7 shows a learning activity on design. It provides background material, guidelines for completing the key artefacts, that describe the outcomes of this learning activity, as well as contact information to group members and instructors. 


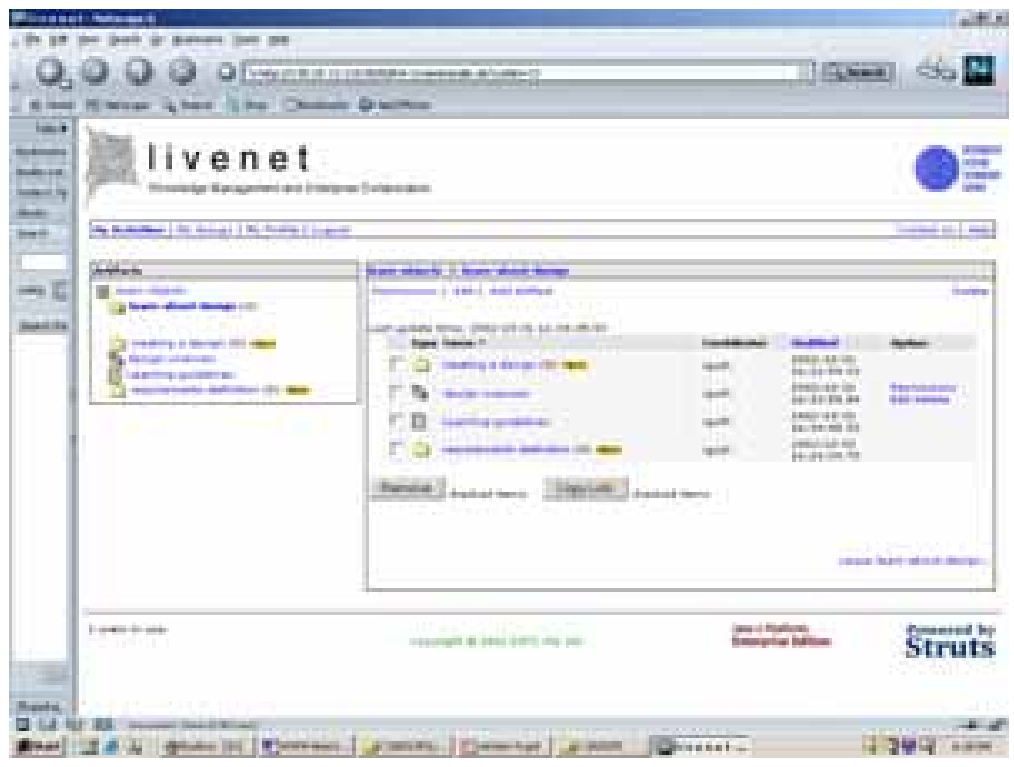

Figure 7 - A workspace for a learning activity

\section{Selecting Services}

The services to support the chosen learning method can be chosen from those available in the learning environment. Figure 8 describes one such set of services. These can be selected as needed and placed in the learning activity workspace. The type of service selected depends on the learning method. Thus a learning method where a group jointly carries out a case study would require services such as chatrooms or discussion systems.

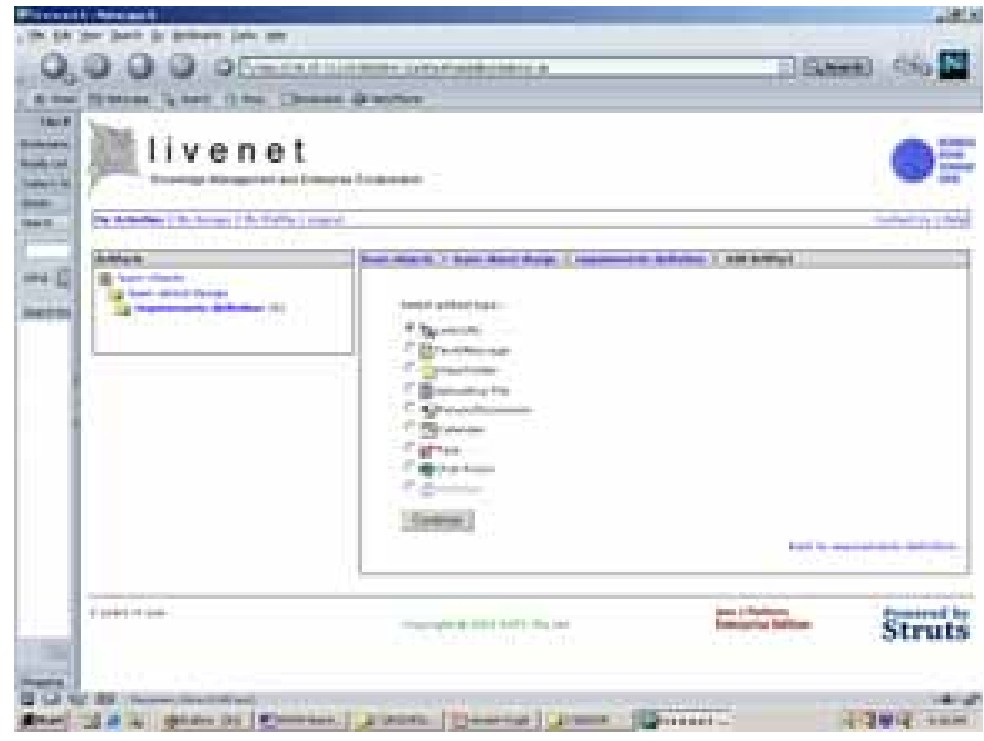

Figure 8 - Available support services 


\section{Managing Activities}

The primary goal of this agent is to expedite the completion of this activity. The learning activity agent primarily encourages participation in the group activity and maintains awareness of progress among group members. It keeps track of changes made to documents, participation in group discussion. Typical rules for this agent include:

Goal: Complete learning-activity on time

Plan: for completing learning-activity on time

Subgoal g1: determine if action is needed to correctly assign role responsibility

Sub plan P1: for g1

Rule R1: on timer alter if no role assigned then action A1

Action A1: send e-mail message to learner and instructor "you should meet and choose someone as the coordinator for learning activity <learningactivity-name>”

Subgoal g2: determine if action needed for work to proceed in a steady manner

Sub plan $P 2$ : for $g 2$

Rule R2: on timer alter if today is later than two days after last update and today is not after the task end date then take action A2

Action A2: send the following message to participant in coordinator role "There seems to be no progress on the key document - should it be updated?"

Rule R3: on timer alter if accesses larger than 15 and no updates to key artifact then action A3. (probably disagreement).

Action A3: send the following message to participants in team-member "You should begin to make changes to the key document”

Subgoal g3: determine if action is needed to improve interaction between team members

Subgoal g4: determine if lack of progress requires some additional learning

The actions to be taken would be derived from rules that evaluate reported outcomes from current learning-activities.

\section{Summary}

The paper described the importance of personalizing learning experiences and ways that agents can be used to manage learning processes. It described the need to have generic agents that can be used to support a large number of learning processes. It then described a way to identify such generic agents using a collaborative metamodel. Learning processes expressed in terms of collaborative concepts can then be supported by such generic objects.

\section{References}

Baylor, A. \& Kim, Y. (2003). Validating pedagogical agent roles: Expert, motivator, and mentor. EDMedia 2003, $15^{\text {th }}$. Annual Conference on Educational Multimedia, Hypermedia and Telecommunications, Hawaii, June.

Hawryszkiewycz, I. T. (2005a). An agent framework for learning systems. Proceedings of the Fourth IASTED International Conference on Web-based Education, Grindelwald, pp. 142-147. 
Hawryszkiewycz, I. T. (2005b). A metamodel for modeling collaborative systems. The Journal of Computer Information Systems, Spring.

Hawryszkiewycz, I. T. \& Lin, A.(2003). Process knowledge support for emergent processes. Proceedings of the Second IASTED International Conference on Information and Knowledge Management, Scottsdale, Arizona, November, pp. 83-87.

Hezemans, M. \& Ritzen, M. (2002). Learning environments: Three types of learning environment. TeleLearning: The Challenge for the Third Millennium, IFIP Congress, Montreal, August 2000, Kluwer Academic Publishers, Boston, pp. 185-192.

Hiltz, R. \& Turoff, M. (2002). What makes learning networks effective? Communications of the ACM, 45(4), 56-59.

Jonassen, D. (1999). Constructivist learning environments on the Web: Engaging students in meaningful learning. EdTech99.

Jonassen, D. \& Rohrer-Murphy, L. (1999). Activity theory as a framework for designing constructivist learning environments. ETR\&D, 47(1), 61-59.

Koper, R. (2000). Modeling units of study from a pedagogical perspective: The pedagogical model behind EML. Retrieved from http://eml.ou.nl/articles

McArdle, G., Monahan, T., Bertolotto, M., \& Mangina, E. (2005). Conceptual agent models for a virtual reality and multimedia e-learning environment. Proceedings of the Fourth IASTED International Conference on Web-based Education, Grindelwald, pp. 119-124.

Müller, J. P. (1996). The design of intelligent agents. Springer Verlag.

Petraglia, J. (1998). The real world on a short term lease: The (Mis)Application of constructivism to the Design of Educational Technology. ETR\&D, 46(3), 53-65.

Wang, F. H. (2005). Developing web-based virtual classroom based on IMS learning design specification. Proceedings of the Fourth IASTED International Conference on Web-based Education, Grindelwald, pp. 267-272.

Wooldridge, M. (1999). Intelligent agents. In G.Weiss (Ed), Multiagent systems. K. M. Carley \& L. Gasser Chapter 1: Computational organization theory.

\section{Biography}

Prof. Hawryszkiewycz is the research leader in the area of collaborative systems at UTS. He completed BE and ME degrees in Electrical Engineering at the University of Adelaide, and a PhD degree at the Massachusetts Institute of Technology. His early research covered the design of databases and information systems for business. Since 1987 his work has focused on collaborative work including the design of collaborative systems with emphasis on knowledge management, including small business networks, or research planning at the World Health Organization (WHO). His team has developed the prototype LiveNet workspace system, which supports collaborative applications. He has over 150 research publications and 3 text books. 